\title{
Coronavirus: Bibliometric analysis of scientific publications from 1968 to 2020
}

\author{
Vasna Joshua ${ }^{1}$, Satish Sivaprakasam*1 (D) \\ Received: 7 May 2020 \\ Published: 20 Jun 2020
}

\section{Abstract}

Background: The World Health Organization declared the outbreak of COVID-19as a public health emergency of international concern on January 30, 2020. Therefore, relevant research metrics would be an added value for understanding the virus for researchers.

Methods: Research outputs related to the Coronavirus were retrieved from the Web of Science database from January 1968 to March 2020 and were analyzed using MS-office, Word Cloud generator, VOS viewer, and ArcGIS software. The analysis was based on the number of research publications per year, contributing author's clustering pattern, most preferred journals, leading publication, document type, broad research areas, commonly used keywords, the geographical distribution of publications, commonly used languages, and productive institutes.

Results: The search retrieved 6424 Coronavirus research publications. The number of articles found in the year 1968 was 1 , but it was 275 in 2019. A total of 33 clusters of authors contributed to studies on COVID-19 across the globe. The Journal of Virology had the most productivityon Coronavirus publications $(\mathrm{n}=810)$. An article published by Ksiazek TG et al in the New England Journal of Medicine had the maximum citation ( $\mathrm{n}=2175) ; 90 \%$ of the research outputs were articles, broadly classified under Infectious diseases $(n=5341)$; and the most commonly used keyword was 'Coronavirus'. The higher number of publications was from the USA ( $\mathrm{n}=2345)$ and the commonly used language was English ( $\mathrm{n}=5948)$, and the most productive institute was the University of Hong Kong ( $\mathrm{n}=506$ ).

Conclusion: The results of the study showed that the growth pattern was not uniform, the United States, and the University of Hong Kong have played a major role in the contribution of Coronavirus research. Even though this depicts a higher scientific growth, it is an alarming sign to the community for preparedness. Under the prevailing situation of seeking better prevention, treatment and vaccination for COVID-19, in-depth research in the above portrayed metrics would be an added knowledge for the researchers.

Keywords: Coronavirus, Bibliometric, Public health, Novel coronavirus, Web of Science, COVID-19

Conflicts of Interest: None declared

Funding: None

*This work has been published under CC BY-NC-SA 1.0 license.

Copyright $@$ Iran University of Medical Sciences

Cite this article as: Joshua V, Sivaprakasam S. Coronavirus: Bibliometric analysis of scientific publications from 1968 to 2020. Med J Islam Repub Iran. 2020 (20 Jun);34:64. https://doi.org/10.47176/mjiri.34.64

\section{Introduction}

Coronaviruses are zoonotic viruses found in mammals

Corresponding author: Satish Sivaprakasam, yessatish@gmail.com

1. Indian Council of Medical Research - National Institute of Epidemiology, Tamil Nadu Housing Board, Ayapakkam, Chennai 600 077, INDIA and birds and infect the respiratory and gastrointestinal

$\uparrow$ What is "already known" in this topic:

Coronavirus disease 2019 (COVID-19), first detected in Wuhan, China, has spread to more than 212 countries across the globe. The World Health Organization has launched a global megatrial called SOLIDARITY on March 20, 2020, an unprecedented coordinated trial designed to collect robust scientific data rapidly during this pandemic.

\section{$\rightarrow$ What this article adds:}

Almost every journal called for papers on COVID-19 and provided them as free access to readers. The Scientific research outputs must have jumped to a greater level. Under the present prevailing situation of the need for robust data, the research metrics of a longer period in countries, journals, institutions, author's clustering pattern, and keywords will be an added value. 
tracts in humans when transmitted. Coronavirus was first identified in the mid-1960sas human pathogens (1). Later zoonotic Coronaviruses have emerged to cause human outbreaks, such as Severe Acute Respiratory Syndrome (SARS) in 2003 and the Middle East Respiratory Syndrome (MERS) since 2012. The virus "SARS-CoV-2" caused the novel Coronavirus disease in 2019 (COVID19) (2). The WHO declared the outbreak of COVID-19 as a public health emergency of international concern on January 30, 2020 (3).

Scientific researchers choose to publish their scientific findings in a journal of their choice to evidence their research work. The current development and new innovative technologies in any research field are authenticated bypeer-reviewed journal publications. In the digital era, the researchers highly focus on publishing their research in journals with wide publicity, high productivity, impact factor, and citations. To measure these research output metrics, tools like bibliometrics, scientometrics etc. are used. This analysis (4) is helpful for researchers to assess the metrics about the history of research, the growth of scientific inventions, and new innovative technologies applied and its pros and cons. In other words, bibliometric analyses are used to describe the study of science, including growth, structure, interrelationships, and productivity of a certain research discipline (5). It brings out the impact of scientific documents, such as research papers, academic journals, reviews, etc.

Gaining knowledge about the current literature available on Coronaviruses across the globe is of high value. There are several databases (Web of Science, Scopus, Google Scholar, etc.) that would bring out the scientific research metrics available in the literature. Our aim was to use the Web of Science database, which is a manually curated database that also tracks more citations (6).

To explore the research metrics of Coronavirus articles published during January 1968 to March 2020 using the Web of Science database.

\section{Methods}

All research output was retrieved from Science Citation Index Expanded, a database of the Thomas Reuters Web of Science from January 1968 to March 2020 by restricting the search under the topic as 'Coronavirus' on March 7, 2020. There were 6424 research outputs during the period. The Journal impact factor was retrieved from Thomson Reuters Journal citation reports 2017.

The data were analyzed using MS-Excel, Word Cloud generator (7), VOS viewer (8), and ArcGIS 10.1 software (9). Data were explored based on the following factors : number of publications according to the year of publication, the author's clustering pattern in the form of a group of networks, articles that were leading publications with their citation, distribution of type of publications, classification of research articles under broad research areas, more commonly used keywords, the geographical distribution of the published research articles, commonly used languages for publication, and predominantly productive institutes for publication of Coronavirus.

The data generated for the study included 53 years of publications and were analyzed with the MS-office, online Word Cloud generator, and VOS viewer.

\section{Results}

Quantification of Coronavirus publication by year

The growth rate of the research output does not show any definite pattern from January 1968 to March2020. The number of publications gradually increased from 1 in 1968 to 388 in 2005during the SARS outbreak. The publications on Coronavirus slowly declined and again increased between 2014 and 2016, marking the outbreak of the MERS. The number of publicationsin 2019 was 275. Figure 1 shows the year-wise growth pattern of the research publications.

The total number of citations for the publication on Coronavirus was 45514 with an average citation of 32.7 per item.

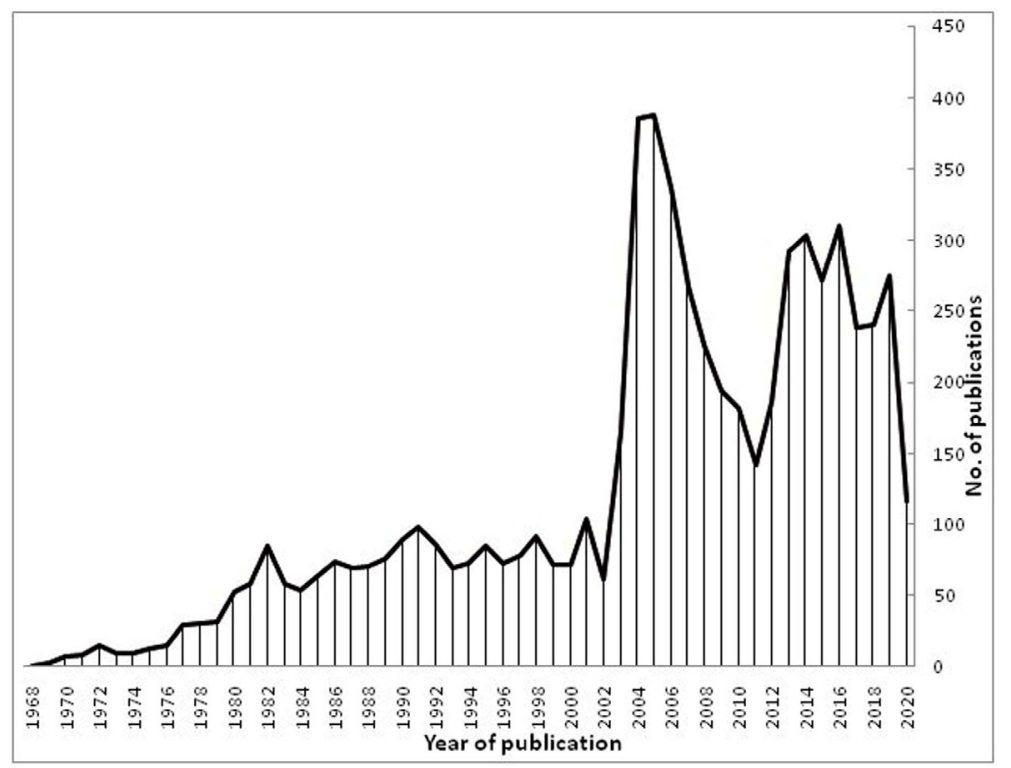

Fig. 1. Year-wise publication of articles on Coronavirus, WOS, 1968-March 2020 
Author's clustering pattern as a group of authors' networks

The pattern of a group of authors' networks is shown by using freely downloadable software, VOS viewer, in Figure 2. It shows the relationship among a unit of an object under study as a graph or network, where the units are the nodes of circles and the relations among them represent a link between 2 nodes. The author as a unit of analysis and coauthorship of articles were visualized with the software, in which the number of appearance of an author's name and different groups is mapped with different colors. As a result, 33 different groups of authors' networks have contributed to COVID-19-related research across the globe, which are shown indifferent colors as identified by the software.

\section{Leading journals in Coronavirus publications and impact factor}

The research outputs were published in 100 different periodicals. The Journal of Virology was the most productive journal with 810 publications $(12.6 \%)$ and an impact factor of 4.368 , followed by the Journal of General Virology $(n=416 ; 6.6 \%)$ and Virology $(n=323 ; 5.0 \%)$. The other top journals contributing to the greatest number of publications and their impact factor are shown in Table 1. Among the top journals contributing to Coronavirus publications, proceedings of the National Academy of Sciences had the highest impact factor of 9.504, followed by

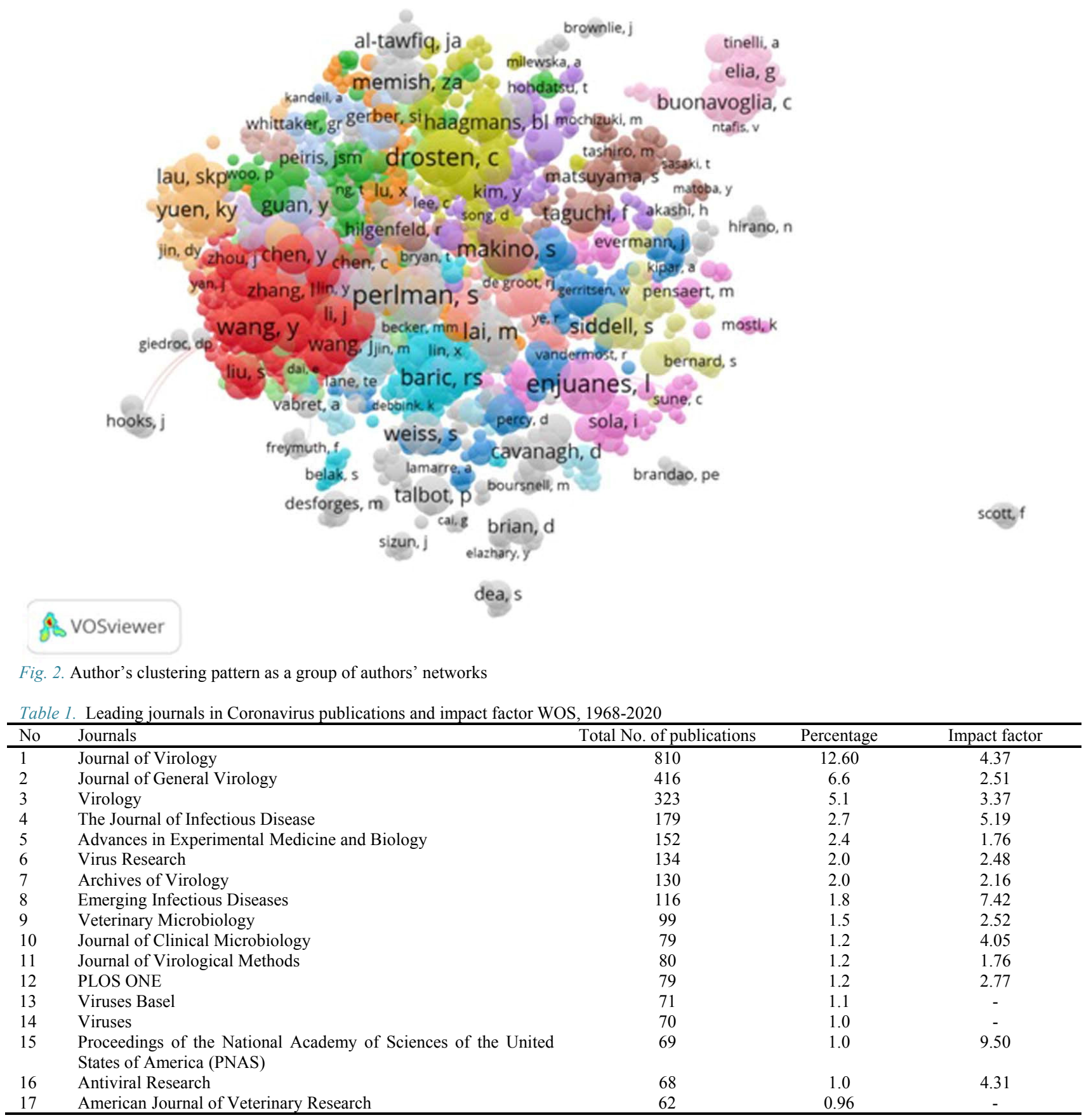


Emerging Infectious Diseases, with 7.422, as per Thomson Reuters Journal citation reports 2017.

Top 10 Coronavirus publications with their citations and mean citation per year

The article "A novel Coronavirus associated with severe acute respiratory syndrome", published in the New England Journal of Medicine by Ksiazek TG et al in 2003, was the most cited $(n=2175)$, with a mean citation of 120.83per year (Table 2). The second highly cited article $(n=2012)$ titled, "Identification of a Novel Coronavirus in patients with severe acute respiratory syndrome", which was also published in the New England Journal of Medicine by Drosten $\mathrm{C}$ et al in 2003 , followed by publications from Science, and the Lancet journals.

The results of analyzing the citations for the top 10 most-cited research papers ( $\mathrm{P} 1$ to $\mathrm{P} 10)$ revealed that all the top-cited articles were published after 2003 and that the papers published during 1968 and 2002 were not much cited. The citations of the articles peaked during 2004 and 2005, except the articleP6, which was published in 2012 (Fig. 3).

\begin{tabular}{|c|c|c|c|}
\hline No. & Publications & $\begin{array}{c}\text { Total } \\
\text { Citations } \\
\end{array}$ & $\begin{array}{l}\text { Mean Citation } \\
\text { Per Year }\end{array}$ \\
\hline$\overline{\mathrm{P} 1}$ & $\begin{array}{l}\text { A novel Coronavirus associated with severe acute respiratory syndrome. N Engl J Med. } 2003 \text { May } \\
15 ; 348(20): 1953-66 \text {. }\end{array}$ & 2175 & 120.83 \\
\hline P2 & $\begin{array}{l}\text { Identification of a Novel Coronavirus in patients with severe acute respiratory syndrome. N Engl J Med. } \\
2003 \text { May 15;348 (20):1967-76. }\end{array}$ & 2012 & 111.78 \\
\hline P3 & $\begin{array}{l}\text { Characterization of a novel Coronavirus associated with severe acute respiratory syndrome. Science. } \\
2003 \text { May 30;300(5624):1394-9 }\end{array}$ & 1747 & 97.06 \\
\hline P4 & $\begin{array}{l}\text { Coronavirus as a possible cause of severe acute respiratory syndrome. Lancet. } 2003 \text { Apr } \\
19 ; 361(9366): 1319-25 \text {. }\end{array}$ & 1670 & 92.78 \\
\hline P5 & $\begin{array}{l}\text { The Genome sequence of the SARS-associated Coronavirus. Science. } 2003 \text { May 30;300(5624):1399- } \\
404 .\end{array}$ & 1536 & 85.33 \\
\hline P6 & $\begin{array}{l}\text { Isolation of a novel Coronavirus from a man with pneumonia in Saudi Arabia. N Engl J Med. } 2012 \text { Nov } \\
8 ; 367(19): 1814-20 .\end{array}$ & 1371 & 152.33 \\
\hline P7 & $\begin{array}{l}\text { Angiotensin-converting enzyme } 2 \text { is a functional receptor for the SARS Coronavirus. Nature. } 2003 \text { Nov } \\
27 ; 426(6965): 450-4 \text {. }\end{array}$ & 1101 & 61.17 \\
\hline P8 & $\begin{array}{l}\text { Isolation and characterization of viruses related to the SARS Coronavirus from animals in southern } \\
\text { China. Science. } 2003 \text { Oct 10;302(5643):276-8. }\end{array}$ & 993 & 55.17 \\
\hline P9 & Bats are natural reservoirs of SARS-like Coronaviruses. Science. 2005 Oct 28; 310(5748):676-9. & 939 & 58.69 \\
\hline $\mathrm{P} 10$ & $\begin{array}{l}\text { Clinical progression and viral load in a community outbreak of Coronavirus-associated SARS pneumo- } \\
\text { nia: a prospective study. Lancet. } 2003 \text { May } \\
\text { 24;361(9371):1767-72. }\end{array}$ & 913 & 50.72 \\
\hline
\end{tabular}

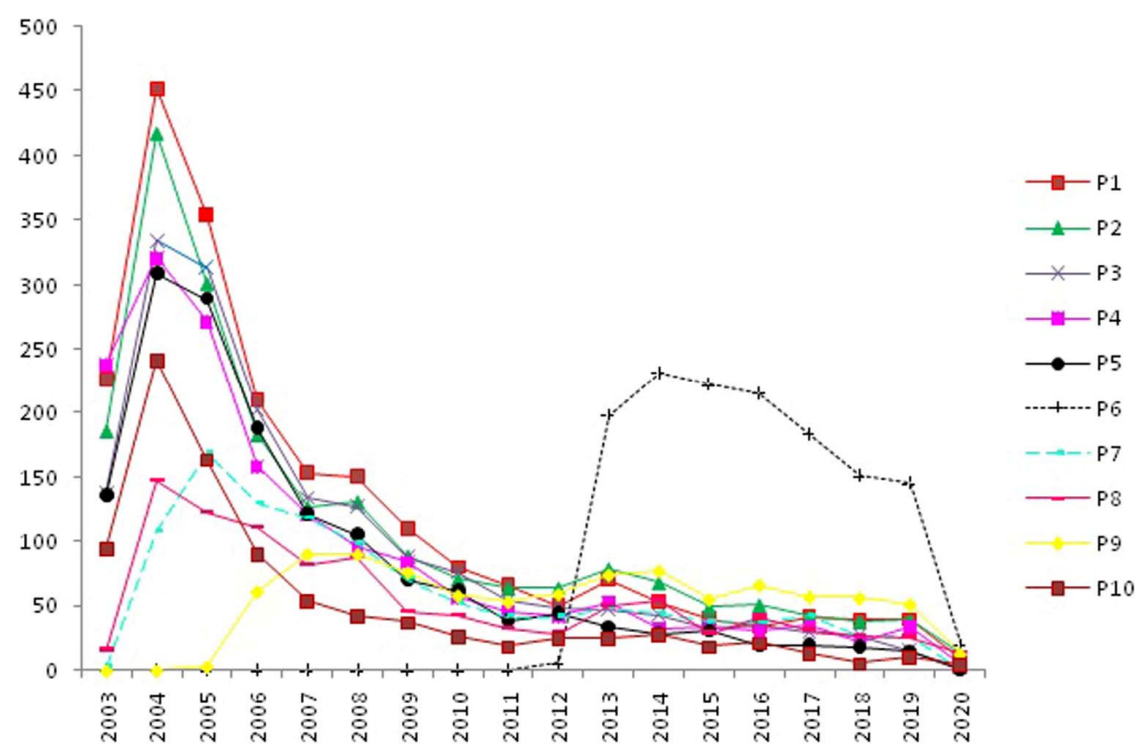

Fig. 3. Top 10 leading publication citations per year from 2003 


\section{Distribution of type of publications}

Out of 6424 publications, almost $90 \%$ of the publications were original articles, followed by $7.4 \%$ review articles, and the rest were abstracts, letters, bibliographies, data papers, and reference materials (Table 3).

Coronavirus articles classified by broad research areas

Each research article has been classified under broad research areas (Table 4). Most of the articles were classified under infectious diseases $(\mathrm{n}=5341 ; 83.14 \%)$, followed by microbiology (5034; 78.36\%), virology (4956; 77.14\%), biochemistry molecular biology $(4195 ; 65.30 \%)$, genetics heredity $(3191 ; 49.67 \%)$ etc.

\section{Keywords}

The authors' keywords were visualized by the freely downloadable software Word cloud (Fig. 4). The size of the font denotes the higher magnitude of keywords used in the research output. The authors used keywords such as Coronavirus, Pneumonia, 2019-nCoV, Novel Coronavirus, COVID-19, public health, Human, Animals, Coronavirus Infection, SARS Coronavirus, SARS virus, Coronaviridae, RNA viral, Nucleotide sequence, Virus infection, Virology, Virus replication, and Middle East Respiratory Syndrome Coronavirus. The most commonly used keywords by the authors were 'Coronavirus' followed by 'Virus', 'Sars', and 'Infection'.

Table 3. Distribution of type of publications on Coronavirus, WOS, 1968- March 2020

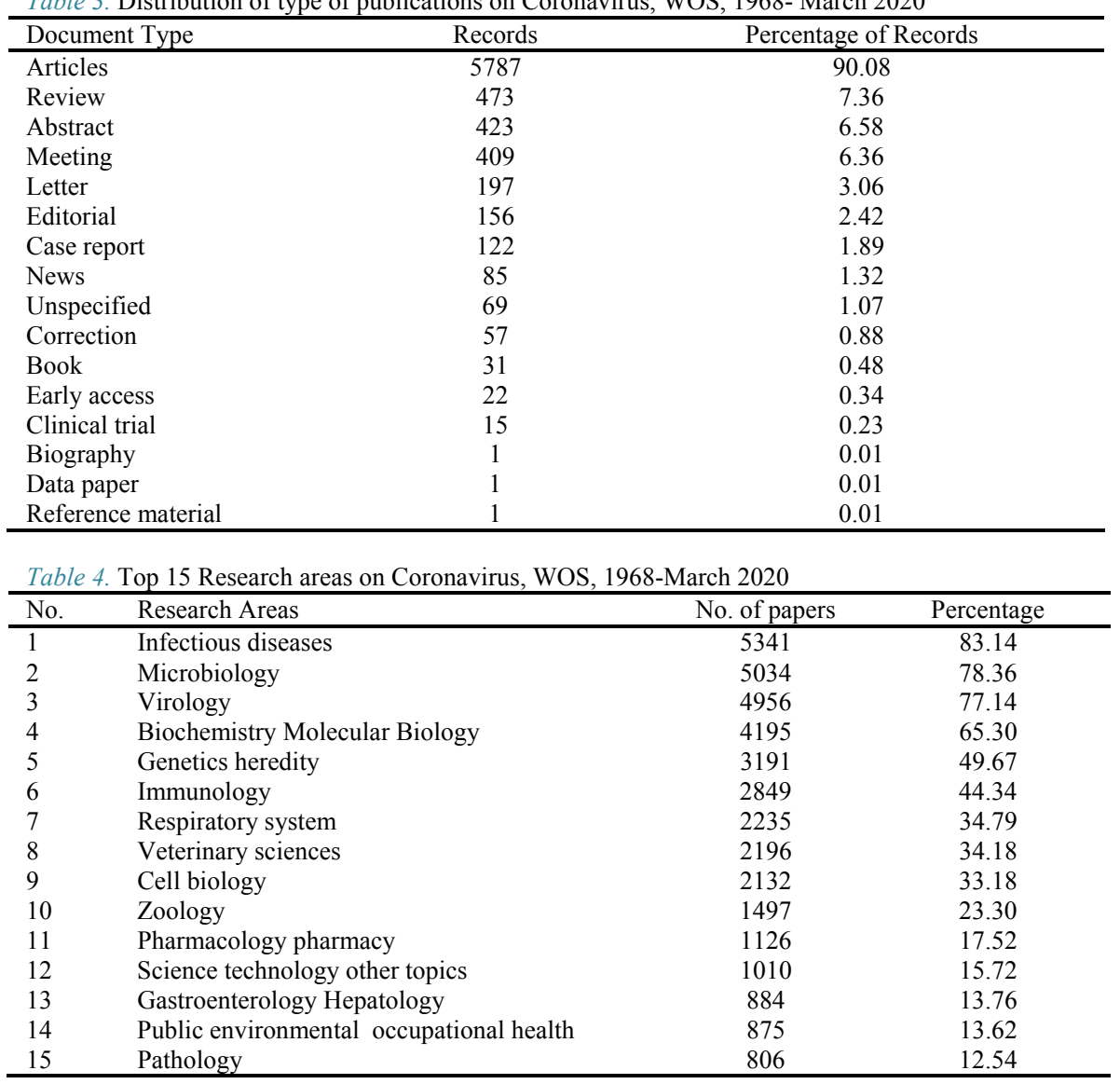

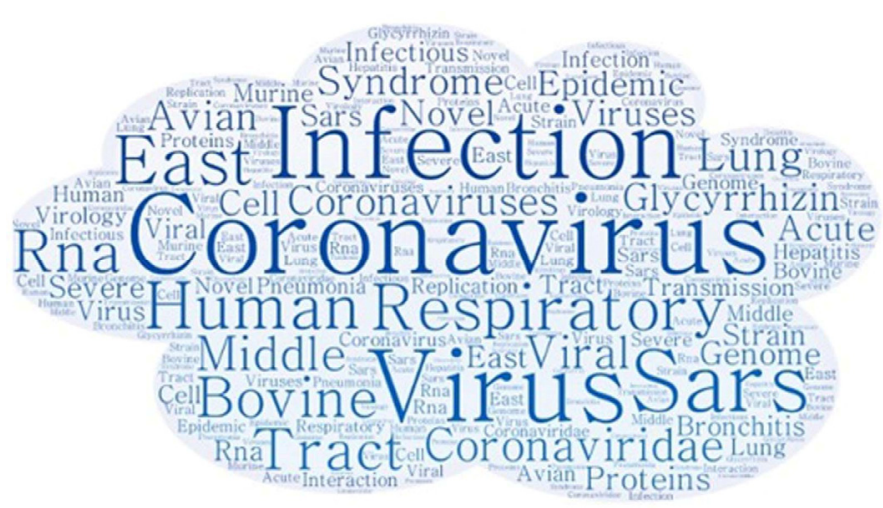

Fig. 4. Author's keywords in Coronavirus research publications, WOS, 1968-March 2020 
Geographical distribution and production of Coronavirus publications

The map (Fig. 5) depicts the geographical distribution of the number of publications of Coronavirus articles at the global level, which was generated using ArcGIS 10.1 software. The regions without any color show regions with no publications. The United States of America $(n=2345 ; 36.5 \%)$ had published the maximum number of articles, followed by China $(n=1067 ; 16.6 \%)$, Germany $(n=480 ; 7.5 \%)$, Netherlands $(n=421 ; 6.6 \%)$, etc.

Publication of Coronavirus research article by language

The publications were in 14 different languages, most of which were in English (92.6\%), followed by French (2.3\%), German (1.5\%), Spanish (1.1\%), etc. (Table 5).

Productive Institute in the publication of Coronavirus research articles

The top 15institutions/organizations that have contributed to Coronavirus research globally are presented in Figure 6 . The University of Hong Kong was the most productive institute with 506 articles $(7.8 \%)$, followed by the University of North Carolina $(n=412 ; 6.4 \%)$, Chinese Academy of Sciences $(n=371 ; 5.8 \%)$, and Utrecht University $(\mathrm{n}=329 ; 5.1 \%)$.

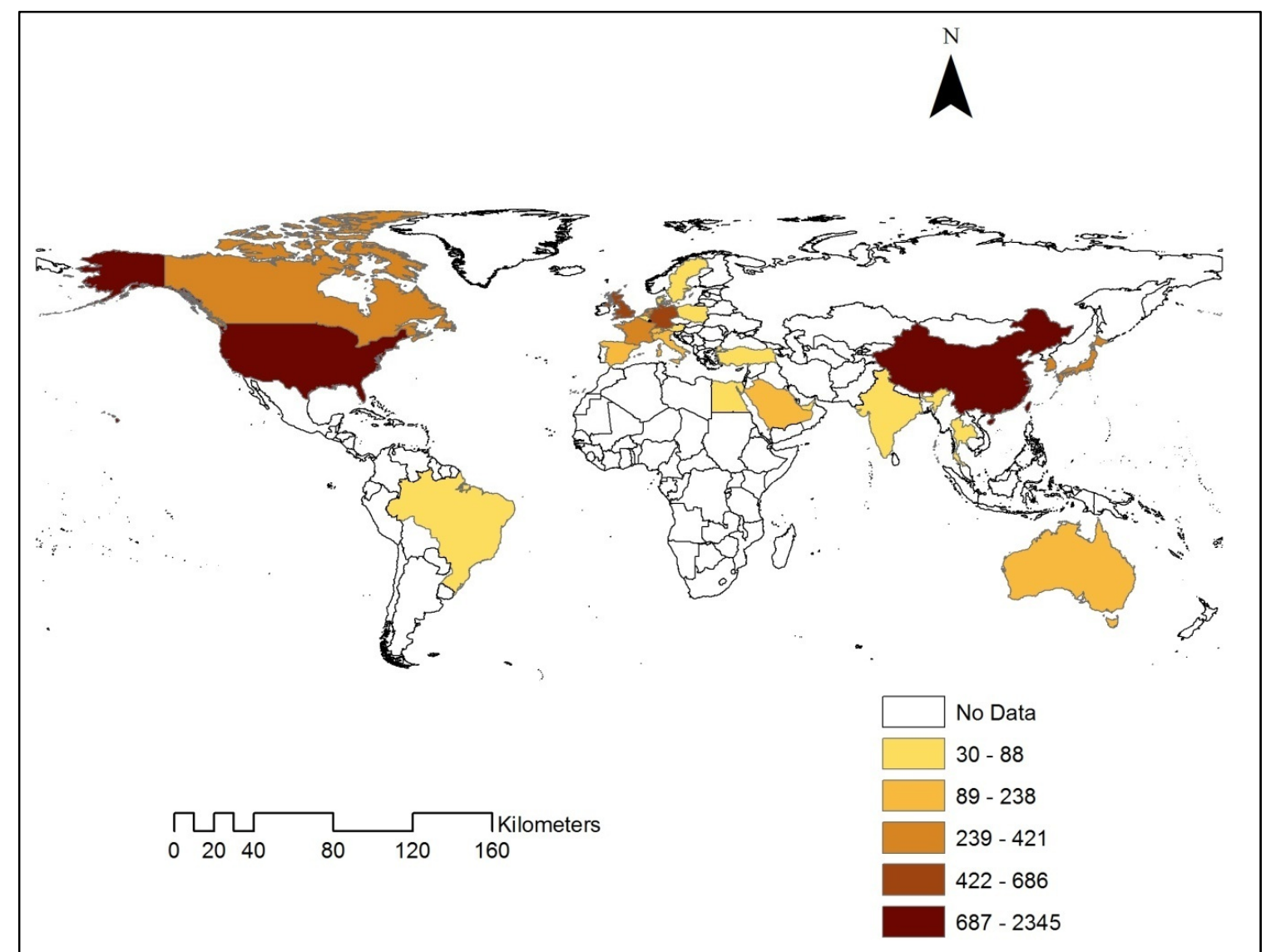

Fig. 5. Geographical distribution of Coronavirus publications, WOS, 1968-March 2020

Table 5. Publication of Coronavirus research article by language, WOS, 1968-March 2020

\begin{tabular}{lccc}
\hline No & Language & Record Count & Percentage \\
\hline 1 & English & 5948 & 92.6 \\
2 & French & 145 & 2.3 \\
3 & German & 97 & 1.5 \\
4 & Spanish & 73 & 1.1 \\
5 & Russian & 42 & 0.7 \\
6 & Korean & 28 & 0.4 \\
7 & Chinese & 19 & 0.3 \\
8 & Portuguese & 16 & 0.2 \\
9 & Hungarian & 12 & 0.18 \\
10 & Dutch & 11 & 0.17 \\
11 & Arabic & 10 & 0.15 \\
12 & Japanese & 10 & 0.15 \\
13 & Italian & 8 & 0.12 \\
14 & Polish & 5 & 0.08 \\
\hline
\end{tabular}




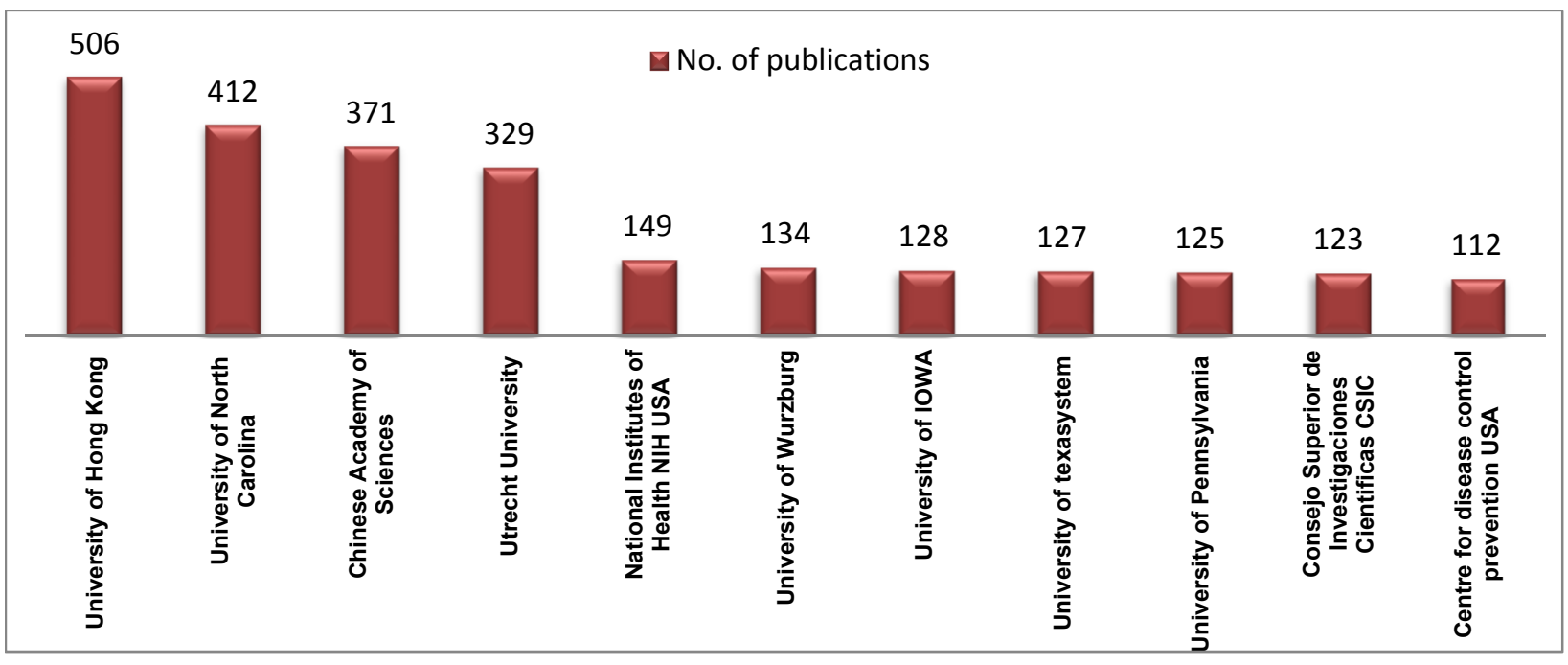

Fig. 6. Top 15 productive institutions in publishing Coronavirus articles, WoS, 1968-Jan 2020

\section{Discussion}

The recent outbreak of the novel Coronavirus disease, COVID-19, in December 2019 was reported in Wuhan, China, creating alarming concerns for the public health, health authorities, and the policymakers. According to the Worldometer lives update as on March 19, 2020, there were 219355 confirmed cases and 8969 deaths from the COVID-19 outbreak (10). The bibliometric analysis on the research topic of Coronavirus using Web of Science database shows an outset picture of the growth pattern of research over 53 years. Only 1 brief annotation article on Coronavirus was published in the Nature journal by Almeida et al in 1968 (11). The article describes the Coronavirus strains and their properties. Although the research publications gradually increased from then on, the citations rapidly increased only during 2003-2004 after the emergence of human transmission of zoonotic Coronaviruses. The research publications were published in nearly 100 different journals as original articles in 14 different languages. The articles were majorly classified under infectious diseases and the most preferred keyword was 'Coronavirus'. The maximum research output was from the United States of America and the most productive institute was the University of Hong Kong.

The findings of our study, which was obtained using the WoS database (1968 to 2019 and 1970 to 2019) (12) Scopus database (1970 to 2019), agreed with several bibliometric analyses (13). A 20-year-span (Jan 2000 to March 2020) of Coronavirus research outputs analyzed through bibliometric methods based on Web of Science pointed 2 sharp increases in research yield after the SARS and MERS outbreaks (14). A bibliometric study (15) evaluated the evolution of knowledge on COVID-19 for 2019 to 2020. Even for a shorter period the leading organizations affiliated with COVID-19 research was the University of Hong Kong. The preferred keyword was 'Coronavirus'.

Another bibliometric study (16) aimed to assess the characteristics of publications involving MERS-CoV dur- ing 2012-15 and showed an increase in the growth of publications, contributing majorly by the USA. An editorial letter (17) about a bibliometric analysis from major biomedical databases from January 1951 to January 2020 for SARS-CoV, MERS-CoV, and novel CoV 2019 found that the USA and China have primary roles in $\mathrm{CoV}$ research, with the USA leading the scientific production with nearly one third of the articles. Even though the time frame analyzed in the above studies was different, the results were similar to our findings. Recent studies $(18,19)$ of shorter duration showed maximum research contributions from China, followed by the United States.

\section{Conclusion}

The growth pattern of research publications shown by our study was not uniform and intermediate peaks were observed in 2005, 2014, 2016, and 2019, which indicated the endemic occurrences, SARS (2003), MERS (2014), and COVID-19 (2019). The top-cited articles were published after 2003 and the citations peaked predominantly in 2004. The USA and the University of Hong Kong were major contributors to the Coronavirus research by region and organization, respectively. Even though this amount of research depicts higher scientific growth, it is an alarming sign to the community for preparedness. Under the prevailing situation of seeking better prevention, treatment and vaccination for COVID-19, in-depth research in the above portrayed metrics would be an added knowledge for the researchers.

\section{Conflict of Interests}

The authors declare that they have no competing interests.

\section{References}

1. Where Did the New Coronavirus Come From? Potentially a Bat, Snake, or Pangolin [Cited 2020 March 8]. Available at: https://www.healthline.com/health-news/Coronavirus-can-be-deadlybut-they-also-cause-the-common-cold-what-to-know. 
2. European Centre for Disease Prevention and Control. [Cited 2020 March 18]

Available at: https://www.ecdc.europa.eu/en/factsheet-healthprofessionals-coronaviruses.

3. Rolling updates on coronavirus disease. [Cited 2020 March 18]. Available at: https:/www.who.int/emergencies/diseases/novelcoronavirus-2019/events-as-they-happen.

4. HoodWW, Wilson C. The literature of bibliometrics, Scientometrics, and informetrics. Scientometrics. 2001;52:291-314.

5. Tague-Sutcliffe J. An introduction to informetrics. Inform Process Manag. 1992;28:13.

6. Yang K, Meho LI. Citation analysis: a comparision of google scholar, scopus, and web of science. Asis\&T. 2007;10:10. [Cited 2020 March 18]Available at https://doi.org/10.1002/meet.14504301185.

7. Freely downloadable. [Cited 2020April 8]. Available athttps://www.wordclouds.com].

8. Freely downloadable. [Cited 2020 April 8]. Available at http://www.vosviewer.com.

9. Environmental Systems Research Institute, Inc. ArcGIS desktop: Release 10. Redlands, CA, USA: ESRI, Inc.; 2010.

10. Coronavirus live update. [Cited 2020 April 8]. Available at https://www.worldometers.info/coronavirus/

11. Aronson JK. Coronaviruses - a general introduction. [Cited 2020 , March 25]. Available at https://www.cebm.net/covid19/coronaviruses-a-general-introduction/

12. Jing-Fei $\mathrm{CH}$, Huai-Zhang WA, Wen-Bo GA, Geng-Yun $\mathrm{CH}$, Liang T. Bibliometric analysis of corona virus research. Med J Chin People's Lib Army. 2020; 45(3):247-55.

13. Ram S. Coronavirus Research Trends: A 50-Year Bibliometric Assessment. Sci Technol Lib. 2020;16:1-7.

14. Zhou Y, Chen L. Twenty-Year Span of Global Coronavirus Research Trends: A Bibliometric Analysis. Int J Environ Res Public Health. 2020;17(9):3082

15. Rajendran L. Coronavirus on veterinary research: a scientometric profile based on CAB direct online. Int J Sci Health Res. 2020;5:159164.

16. Zyoud SH. Global research trends of Middle East respiratory syndrome coronavirus: a bibliometric analysis. BMC Infect Dis. 2016;16: 255.

17. Bonilla-Aldana DK, Quintero-Rada K, Montoya-Posada JP, Ramírez-Ocampo S, Paniz-Mondolfi A, Rabaan A, et al. SARS-CoV, MERS-CoV and now the 2019-novel CoV: Have we investigated enough about coronaviruses? - A bibliometric analysis. Travel Med Infect Dis. 2020;33.

18. Rafiei Nasab F, Rahim F. Bibliometric Analysis of Global Scientific Research on SARSCoV-2 (COVID-19). medRxiv. 2020;Jan 1.

19. Dehghanbanadaki H, Seif F, Vahidi Y, Razi F, Hashemi E, Khoshmirsafa M, et al. Bibliometric analysis of global scientific research on Coronavirus (COVID-19). Med J Islam Repub Iran. 2020;34(1):35462 . 